\title{
RELAÇÕES DA EROSÃO EM ENTRESSULCOS COM O TIPO E COM A QUANTIDADE DE RESÍDUO VEGETAL NA SUPERFÍCIE DO SOLO(1)
}

\author{
J . A. BRAIDA(2) \& E. A. CASSOL ${ }^{(3)}$
}

\begin{abstract}
RESUMO
Os resíduos vegetais na superfície do solo são muito efetivos em dissipar a energia de impacto das gotas de chuva, além de constituírem barreira física ao livre escoamento superficial da água. A presença desses resíduos em contato direto com a superfície do solo pode influenciar, decisivamente, a erosão em entressulcos. Este estudo objetivou avaliar as relações da er osão em entressulcos com a quantidade de resíduo vegetal em cobertura e verificar as diferenças nessas relações para palha de milho e palha de trigo. Um experimento de campo foi instalado no Centro de Pesqui sa de Florestas e Conservação do Solo da FEPAGRO, em Santa Maria, RS, em Podzólico Vermelho-E scuro franco-arenoso. As parcelas experimentais mediam $0,50 \times 0,75 \mathrm{~m}$, com a maior di mensão no sentido do declive do terreno, que era de $0,17 \mathrm{~m} \mathrm{~m}^{-1}$, arranjadas em quatro blocos completos ao acaso. Palhas de milho e de trigo, picadas em fragmentos de 7,5 cm, foram distribuídas, nas parcelas, sobre solo recentemente preparado, em quantidades de $0,00,0,05,0,10,0,20,0,40$ e $0,80 \mathrm{~kg} \mathrm{~m}^{-2}$. Em seguida, foi aplicada uma chuva si mulada de intensidade média de $67 \mathrm{~mm} \mathrm{~h}^{-1}$ e duração de $90 \mathrm{~min}$. As taxas de perdas de solo e água por erosão em entressulcos variaram ao longo da chuva, dependendo da quantidade de resíduo vegetal existente na superfície do solo, porém não foram observadas variações si gnificativas em relação ao tipo de palha. A relação da erosão em entressul cos com a fração do solo coberto (dada em função da quantidade de palha) pode ser expressa por meio de uma equação exponencial. Por ser um modelo simples, com medi das de fácil obtenção, sugere-se esse modelo para estimar o subfator cobertura do solo em entressulcos por resíduos em contato direto com a superfície.
\end{abstract}

Termos de indexação: erosão hídrica, cobertura do solo.

(1) Artigo extraído da Tese de Mestrado do primeiro autor, sob a orientação do segundo autor, apresentada e aprovada no Curso de Pós-Graduação em Ciência do Solo do PPGAg da Universidade Federal do Rio Grande do Sul - UFRGS. Trabalho realizado com recursos parciais da Fundação de Amparo à Pesquisa do Estado do Rio Grande do Sul (FAPERGS) eapresentado no XIII Congresso Latino Americano de Ciência do Solo, realizado em Águas de Lindóia (SP), de 04 a 08 de agosto de 1996. Recebido para publicação em dezembro de 1997 e aprovado em abril de 1999.

(2) Professor Assistente do Curso de Agronomia do Centro F ederal de EducaçãoTecnológica do Paraná (CEFET-PR), Unidade de Pato Branco. Caixa Postal 571, CEP 85503-390 Pato Branco (PR). Email: braidaja@cefet.whiteduck.com.br.

(3) Professor Adjunto do Departamento de Sol os da Faculdade deAgronomia, UFRGS, Caixa Postal 776, CEP 90001-970, Porto Alegre (RS) e Pesquisador da Fundação Estadual de Pesquisa Agropecuária (FEPAGRO). Rua Gonçalves Dias, 570, CEP 90130-060, Porto Alegre (RS). Bolsista do CNPq. Email: Cassolea@orion.ufrgs.br. 


\title{
SUMMARY: RELATIONSHIP OF INTERRILL EROSION TO TYPE AND AMOUNT OF CROP RESIDUE ON SOIL SURFACE
}

\begin{abstract}
Crop residue in direct contact with the soil surface is very effective in dissipating the energy of raindrop impact on soil, being also a physical barrier against interrill overland flow. The presence of these residues may strongly affect the interrill soil erosion process. A study was carried out with the objective of evaluating the relationship between interrill erosion and amounts of crop residue in direct contact with soil surface and to verify the differences in this relationship for corn and wheat residues. An experiment was conducted at theF orest and Soil Conservation Research Center of FEPAGRO, in Santa Maria, RS, on a Paleudult sandy loam soil. Experimental interrill pl ots of $0.50 \times 0.75 \mathrm{~m}$, with thelargest dimension parallel to thedirection of land sl ope of $0.17 \mathrm{~m} \mathrm{~m}^{-1}$, werearranged in 4 completely random bl ocks. Residues of corn and wheat chopped in pieces of about $7.5 \mathrm{~cm}$ weredistributed over the plots on freshly tilled soil, at amounts of $0.00,0.05,0.10,0.20,0.40$ and $0.80 \mathrm{~kg} \mathrm{~m}^{-2}$. Simulated rainfall was applied at a mean intensity of $67 \mathrm{~mm} \mathrm{~h}^{-1}$, during 90 mi nutes. There was a significant variation of interrill soil and water losses with the time of rainfall and with amount of crop residues. However, therewas no variation with thetype of residue. The relationship between interrill soil loss and amount of residue in direct contact with soil surface fitted well to an exponential equation. This exponential model is recommended to estimate the subfactor interrill soil cover by residues in direct contact with the surface, because it is easy to use and obtain measurements.
\end{abstract}

Index terms: soil erosion by water, interrill erosi on, soil cover, residueground cover.

\section{NTRODUÇÃO}

O processo de erosão hídrica pode ser dividido em erosão em entressulcos e erosão em sulcos, dependendo das condições superficiais em que ocorre e da forma de atuação do agente erosivo (Ellison, 1947; Meyer et al., 1975). A erosão em entressulcos éessencial menteindependente da erosão nos sulcos, ocorrendo em pendentes relativamente curtas e geralmente orientadas segundo o microrrel evo superficial. Nessas áreas, o fluxo do escoamento superficial é uniforme e ocorre na forma de fluxo superficial raso, que contribui para o fluxo concentrado nos sulcos (Meyer et al., 1975; F oster, 1982).

Nos entressulcos, a desagregação de partículas da massa do solo é, conceitualmente, realizada exclusivamente pel o impacto das gotas de chuva. A energia cinética das gotas de chuva gera intensas forças de pressão ecisal hamento, local izadas no ponto de impacto, que podem desagregar grandes quantidades de partículas do solo (Ellison, 1947; Al Durrah \& Bradford, 1982). O transportedas partículas desagregadas éreal izado, quase que exclusivamente, pel o fluxo superficial raso. I solado, tal fluxo mostra capacidade detransporte muitolimitada, porém, sob a ação do impacto das gotas da chuva, essa capacidade éaumentada consideravel mente. O impacto das gotas de chuva produz turbulência no fluxo superficial, suspendendo e mantendo suspensas as partículas de solo desagregado (Ellison, 1947; Kinnel, 1988).
A presença de resíduos vegetais na superfície do solo aumenta a rugosidade hidráulica dessa superfície, reduzindo a velocidade e aumentando a profundidade do fluxo superficial (Foster, 1982). Assim, esse tipo de cobertura do sol o reduz a erosão em entressulcos a partir de três efeitos: (a) impedindo o impacto direto das gotas de chuva na superfície do solo, principal fonte de energia de desagregação nessas áreas; (b) reduzindo a capacidade de transporte do fluxo superficial, pela redução de sua velocidade, e (c) aumentando a profundidade do fluxo que, então, pode dissipar a energia de impacto das gotas da chuva (Mutchler \& Young, 1975), reduzindo a taxa de desagregação.

Foster (1982) propôs que a taxa de desagregação de solo em entressulcos, na presença de resíduos vegetais na superfície do solo, pode ser estimada a partir da equação:

$$
D_{i}=K_{i} \cdot i^{2} \cdot S_{f} \cdot C_{i}
$$

em que $D_{i}$ é a taxa de desagregação de solo em entressul cos $\left(\mathrm{kg} \mathrm{m}^{-2} \mathrm{~s}^{-1}\right)$; $\mathrm{K}_{\mathrm{i}}$ é a erodibilidade do solo para erosão em entressulcos $\left(\mathrm{kg} \mathrm{s} \mathrm{m}^{-4}\right)$; i é a intensidade da chuva $\left(\mathrm{m} \mathrm{s}^{-1}\right) ; \mathrm{S}_{\mathrm{f}}$ é o coeficiente do fator declividade do solo, e $C_{i}$ é o coeficiente do fator cobertura do solo.

Conforme Liebenow et al. (1990), o fator declividade do solo pode ser estimado pela seguinte equação:

$$
\mathrm{S}_{\mathrm{f}}=1,05-0,85 \cdot \mathrm{e}^{-4 \operatorname{sen} \Omega}
$$


em que $\mathrm{S}_{\mathrm{f}}$ é o fator declividade do solo; eé a base do logaritmo natural, e $\Omega$ é o ângulo do declive.

Segundo F oster (1982), o fator cobertura do solo em entressul cos podeser determinado pela seguinte expressão:

$$
\mathrm{C}_{\mathrm{i}}=\mathrm{C}_{\mathrm{il}} \cdot \mathrm{C}_{\mathrm{ill}} \cdot \mathrm{C}_{\mathrm{illl}}
$$

em que $C_{i}=$ fator cobertura do solo; $C_{i l}=$ efeito da cobertura dada pelo dossel das culturas; $\mathrm{C}_{\mathrm{ill}}=$ efeito da cobertura dada por resíduos em contato direto com a superfície do solo, e $\mathrm{C}_{\text {ill }}=$ efeito dos resíduos incorporados ao solo, conforme proposto por Wischmeier (1975).

O subfator $C_{i l l}$, que representa o efeito da cobertura por resíduos em contato direto com a superfície do solo, pode ser estimado, segundo F oster (1982), pela seguinte expressão:

$$
\mathrm{C}_{\mathrm{ill}}=\xi \cdot \exp \left\{-0,21 \cdot\left[\left(\mathrm{y}_{\mathrm{c}} / \mathrm{y}_{\mathrm{d}}\right)-1\right]^{1,18}\right\}
$$

em que $C_{i l l}$ é o subfator cobertura do solo para resíduos em contato direto com a superfície; $\xi$ é a fração da superfície exposta ao impacto direto das gotas de chuva, e $y_{d} / y_{d}=$ razão da altura da lâmina de água na superfície com cobertura $\left(\mathrm{y}_{\mathrm{c}}\right)$ e sem cobertura $\left(\mathrm{y}_{\mathrm{d}}\right)$.

Esta equação considera que, com a presença de cobertura em contato direto com o solo, a desagregação só ocorre na fração descoberta da superfície exposta ao impacto direto das gotas de chuva. Considera, ainda, que, nessa fração da superfície, a taxa de desagregação é reduzida pelo aumento da profundidade do fluxo superficial, ou seja, a profundidade do fluxo superficial no solo coberto será sempre maior que no solo descoberto.

Laflen et al. (1985) propõem que o fator $C_{i l l}$ seja estimado pela equação:

$$
\mathrm{C}_{\mathrm{ill}}=\mathrm{e}^{2,5} \cdot \mathrm{CS}
$$

em que $C_{i l l}=$ subfator cobertura do solo em contato direto com a superfície do solo; e=base do logaritmo natural, e $\mathrm{CS}=$ cobertura do solo $\left(\mathrm{m}^{2} \mathrm{~m}^{-2}\right)$. Essa relação é bastante simples e, por meio dela, o fator $\mathrm{C}_{\text {ill }}$ (cobertura por resíduos em contato direto com a superfície do solo nas áreas em entressulcos) depende apenas da fração do sol o coberto.

Cogo (1981) e Lopes et al. (1987), estudando o processo de erosão hídrica de forma global, não separando a erosão em entressulcos da erosão em sulcos, em parcelas do tipo USLE, encontraram diferenças na eficácia de controle da erosão hídrica do sol o pel os resíduos de trigo, mil ho esoja. Segundo esses autores, tais diferenças estão relacionadas com as características dos resíduos vegetais, tais como: tamanho, forma e densidade dos fragmentos de pal ha que formam esses resíduos. Foster et al. (1982) verificaram que o aumento na rugosidadehidráulica da superfície do solo varia com o tipo e com a quantidade de resíduo vegetal.
Neste aspecto, há deficiência de informações sobre as relações da erosão em entressulcos com quantidade e, principalmente, tipos de resíduos vegetais. Considerando a capacidade dos resíduos vegetais em reduzir a manifestação do potencial erosivo do impacto das gotas de chuva e em reduzir a velocidade do fluxo superficial, torna-seimportante o estudo dessas relações.

Esteestudo objetivou estudar as relações da erosão em entressulcos com a quantidade de resíduo vegetal em cobertura everificar se essas relações variam para cobertura com palha de milho e com palha de trigo.

\section{MATERIAL E MÉTODOS}

Trabalhos experimentais de campo foram realizados, em fevereiro de 1993, no Centro de Pesquisa de Florestas e Conservação do Solo da Fundação Estadual de Pesquisa Agropecuária (FEPAGRO) do estado do Rio Grande do Sul, município de Santa Maria, na região fisiográfica da Depressão Central do estado do Rio Grande do Sul, situada entre as latitudes $29^{\circ} 30^{\prime}$ e $29^{\circ} 45^{\prime}$ Sul e longitudes $54^{\circ} 00^{\prime}$ e $54^{\circ} 15^{\prime}$ a Oeste de Greenwich. $O$ clima édotipo $\mathrm{Cfa}$, subtropical ou quase temperado, úmido sem estiagem. O sol o da área é um Podzólico Vermel ho-E scuro (Abrão et al., 1988). No quadro 1, encontram-se algumas características físicas e químicas da camada arável do solo da área experimental $(0-20 \mathrm{~cm})$.

O trabalho fez parte de um estudo mais amplo realizado por Braida (1994), em que se encontram pormenores do procedimento experimental. Neste experimento, pal ha de milhoe palha detrigo, picadas em fragmentos de tamanho médio de $7,5 \mathrm{~cm}$, foram distribuídas, em parcelas de 0,50 × 0,75 m, sobre sol o recém-preparado. A declividade média das parcelas era de 0,17 m m-1. As parcelas, arranjadas em quatro blocos completos ao acaso, foram delimitadas nas laterais e extremidade superior por uma chapa metálica em forma de " $U$ "e, na extremidade inferior, por uma calha coletora. As quantidades de palha empregadas foram de $0,00,0,05,0,10,0,20,0,40$ e $0,80 \mathrm{~kg} \mathrm{~m}^{-2}$. Sobreas parcel as foi aplicada uma chuva simulada de intensidade média de $67 \mathrm{~mm} \mathrm{~h}^{-1} \mathrm{e}$ duração de $90 \mathrm{~min}$, utilizando-se o simulador de chuvas de braços rotativos descrito por Cassol \& Guerra (1978).

A intensidade da chuva foi medida por meio de pluviômetros col ocados junto à extremi dadesuperior das parcelas. Antes dos testes, determinou-se a declividade de cada parcela. Após a distribuição das doses de palha, as parcel as foram fotografadas para determinar a cobertura do sol o pel o método proposto por Mannering edescrito por Lopes (1984). Durante a chuva, coletou-se toda a enxurrada proveniente das parcelas, utilizando potes plásti cos col ocados na 
Quadro 1. Características físicas e químicas do horizonte superficial do solo da área experimental

\begin{tabular}{|c|c|}
\hline Argila $(<0,002 \mathrm{~mm})^{(1)}\left(\mathrm{kg} \mathrm{kg}^{-1}\right)$ & 0,144 \\
\hline Silte $(0,002-0,050 \mathrm{~mm})^{(1)}\left(\mathrm{kg} \mathrm{kg}^{-1}\right)$ & 0,101 \\
\hline Areia $(0,050-2,00 \mathrm{~mm})^{(1)}\left(\mathrm{kg} \mathrm{kg}^{-1}\right)$ & 0,755 \\
\hline Areia muito fina $(0,105-0,050 \mathrm{~mm})^{(1)}\left(\mathrm{kg} \mathrm{kg}^{-1}\right)$ & 0,080 \\
\hline Areia fina $(0,25-0,105 \mathrm{~mm})^{(1)}\left(\mathrm{kg} \mathrm{kg}^{-1}\right)$ & 0,283 \\
\hline Areia média $(0,50-0,25 \mathrm{~mm})^{(1)}\left(\mathrm{kg} \mathrm{kg}^{-1}\right)$ & 0,310 \\
\hline Areia grossa $(1,00-0,50 \mathrm{~mm})^{(1)}\left(\mathrm{kg} \mathrm{kg}^{-1}\right)$ & 0,076 \\
\hline Areia muita grossa $(2,00-1,00 \mathrm{~mm})^{(1)}\left(\mathrm{kg} \mathrm{kg}^{-1}\right)$ & 0,006 \\
\hline $\mathrm{D}_{50}$ das partículas do solo disperso $(\mathrm{mm})$ & 0,194 \\
\hline Densidade do solo ${ }^{(1)}\left(\mathrm{kg} \mathrm{m}^{-3}\right)$ & 1.510 \\
\hline Densidade da partícula(1) $\left(\mathrm{kg} \mathrm{m}^{-3}\right)$ & 2.650 \\
\hline Porosidade total ${ }^{(1)}\left(\mathrm{m}^{3} \mathrm{~m}^{-3}\right)$ & 0,430 \\
\hline Teor de matéria orgânica ${ }^{(2)}\left(\mathrm{kg} \mathrm{kg}^{-1}\right)$ & 0,010 \\
\hline pH em água ${ }^{(2)}$ & 4,51 \\
\hline Capacidade de troca de cáti ons ${ }^{(2)}\left(\mathrm{mmol}_{\mathrm{c}} \mathrm{kg}^{-1}\right)$ & 38 \\
\hline Teor de $\mathrm{Al}^{(2)}\left(\mathrm{mmol}_{\mathrm{C}} \mathrm{kg}^{-1}\right)$ & 6 \\
\hline Teor de $\mathrm{Ca}^{(2)}\left(\mathrm{mmol}_{\mathrm{cg}} \mathrm{kg}^{-1}\right)$ & 12 \\
\hline Teor de $\mathrm{Mg}^{(2)}\left(\mathrm{mmol}_{\mathrm{c}} \mathrm{kg}^{-1}\right)$ & 6 \\
\hline
\end{tabular}

(1) Determinações efetuadas conforme EMBRAPA (1979).

(2) Determinações efetuadas conforme Tedesco et al. (1985).

saída da cal ha coletora. Os potes foram trocados de três em três minutos nos primeiros 15 min de chuva e, depois, de dois em dois minutos. As taxas de perdas de solo e água, bem como a concentração de sedimentos na enxurrada, foram calculadas a partir da pesagem dos potes que continham as amostras col etadas, antes e após a secagem em estufa a $65^{\circ} \mathrm{C}$.

A velocidade do fluxo superficial foi medida nas parcelas correspondentes aos tratamentos sem adição de palha. Para tanto, adicionou-se corante azul de metileno ao fluxo a $40 \mathrm{~cm}$ da extremidade inferior da parcela, cronometrando-se o tempo que o fluxo gastou para percorrer essa distância. A vel ocidade média do fluxo é a média aritmética das velocidades medidas a 5, 10, 15, 30, 45, 60, 75 e 89 min do início dos testes.

A taxa deerosão em entressul cos foi considerada como sendo igual à taxa de desagregação e foi determinada para cada intervalo de amostragem, dividindo-se a massa de sol o erodido por unidade de tempo $\left(\mathrm{kg} \mathrm{s}^{-1}\right)$ pela área da parcela $\left(0,375 \mathrm{~m}^{2}\right)$, sendo expressa em $\mathrm{kg} \mathrm{m}^{-2} \mathrm{~s}^{-1}$.

O subfator $\mathrm{C}_{\mathrm{ill}}$ foi calculado, considerando que os subfatores $C_{i l}$ e $C_{i l \mid l}$ eram iguais à unidade, por não haver cobertura aérea (dossel) nem incorporação de resíduos vegetais. A equação utilizada foi:

$$
C_{i l l}=D_{\text {imax }} /\left(K_{i} \cdot i^{2} \cdot S_{f}\right)
$$

em que $C_{i l l}=$ subfator relativo à cobertura do solo em contato direto com a superfície; $D_{\text {imax }}=$ taxa máxima de erosão em entressul cos $\left(\mathrm{kg} \mathrm{m}^{-2} \mathrm{~s}^{-1}\right) ; \mathrm{K}_{\mathrm{i}}=$ erodibilidade do solo em entressul cos ( $\left.\mathrm{kg} \mathrm{s} \mathrm{m}^{-4}\right) ; \mathrm{i}=$ intensidade da chuva $\left(\mathrm{m} \mathrm{s}^{-1}\right), \mathrm{eS}_{\mathrm{f}}=$ fator declividade do solo.
A taxa máxima de erosão em entressulcos foi determinada para cada tratamento, por meio do ajuste de model os matemáticos aos dados observados. Foi utilizado o valor do fator erodibilidade em entressulcos de $\mathrm{K}_{\mathrm{i}}=5,10 \times 10^{6} \mathrm{~kg} \mathrm{~s} \mathrm{~m}^{-4}$, determinado a partir de dados obtidos neste mesmo experimento, conforme descrito por Braida \& Cassol (1996). O fator declividade do sol o foi estimado pela equação 2.

Para a estimação do fator $C_{i l l}$, por meio da equação (4), deve-se determinar a altura da lâmina de água no sol o com cobertura e relacioná-la com a altura da lâmi na deágua nosolo descoberto. A altura da lâmina de água nas parcel as com sol o descoberto, nas quais se mediu a vel ocidade do fluxo superficial, foi calculada a partir da equação da continuidade ( $Q=A$ v), dada por Chow (1959), considerando quea área $(A)$ da seção transversal de fluxo superficial raso é dada por $\mathrm{A}=\mathrm{I}$ y. Reordenando os termos, obtém-se:

$$
\mathrm{y}=\mathrm{Q} /(\mathrm{I} . \mathrm{v})
$$

em que y é a altura da lâmina de água (m); $Q$ é a taxa de descarga $\left(\mathrm{m}^{3} \mathrm{~s}-1\right)$; $v$ é a velocidade do fluxo superficial $\left(\mathrm{m} \mathrm{s}^{-1}\right)$, el =largura do fluxo $(\mathrm{m})$.

Para as parcelas com resíduos vegetais, a altura da lâmina de água foi estimada a partir da equação da velocidade ( $v$ ) de Manning, ( $\left.v=R^{2 / 3} \mathrm{~s}^{1 / 2} / \mathrm{n}\right)$, considerando que, para fluxos rasos, or raio hidráulico (R) é aproximadamente igual à profundidade (y) do fluxo (Chow, 1959). Sabendo que a taxa de descarga por unidade de largura do fluxo (q) é dada por $q=Q /$ (em que $\mathrm{Q}=$ taxa de descarga el =largura do fluxo) e considerando $v=q / y$, substituindo esta expressão na equação deManning efazendo os reordenamentos necessários a partir da equação (7), obtém-se:

$$
y=\left[(n \cdot q) /\left(s^{1 / 2}\right)\right]^{3 / 5}
$$

em que y = altura da lâmina de água $(m) ; n=$ coeficiente de rugosidade hidráulica de Manning $\left(\mathrm{s} \mathrm{m}^{-1 / 3}\right) ; \mathrm{q}=$ taxa de descarga por unidade de largura $\left(\mathrm{m}^{2} \mathrm{~s}^{-1}\right)$, es $=$ declividade superficial $\left(\mathrm{m} \mathrm{m}^{-1}\right)$.

O coeficiente de rugosidade hidráulica de Manning ( $\mathrm{n}$ ), na presença de resíduos vegetais em cobertura, foi estimado por meio das expressões propostas por F oster et al. (1982):

$$
\begin{gathered}
n=n_{s}+n_{r} \\
n_{r t}=0,469 \cdot M R 1,60 \\
n_{r m}=0,105 . M R 0,94
\end{gathered}
$$

em que $n=$ coeficiente de rugosidade hidráulica de Manning; $n_{s}=$ coeficiente de rugosidade hidráulica devida ao solo; $n_{r}=$ coeficiente de rugosidade hidráulica devida ao resíduo vegetal em cobertura; $\mathrm{n}_{\mathrm{rt}}=$ coeficiente de rugosidade hidráulica devida à palha de trigo; $n_{r m}=$ coeficiente de rugosidade hidráulica devida à pal ha de milho, e MR = massa de resíduos $\left(\mathrm{kg} \mathrm{m}^{-2}\right)$. 
O coeficiente $\mathrm{n}_{\mathrm{s}}$ foi calculado pela equação de Manning a partir dos dados de velocidade do fluxo superficial, obtidos nas parcelas sem resíduos vegetais em cobertura.

\section{RESULTADOS E DISCUSSÃO}

No quadro 2, são apresentadas a cobertura do sol o ea concentração média de sedimentos na enxurrada em entressulcos, proporcionadas por diferentes quantidades de palha de trigo e palha de milho picadas e distribuídas na superfície do solo.

Para os dois tipos de pal ha, observou-sequehouve aumento da cobertura do solo com o aumento da quantidade de pal ha empregada. Esse aumento foi proporcional mente maior nas quantidades menores que $0,40 \mathrm{~kg} \mathrm{~m}^{-2}$, em que a sobreposição de peças de resíduo foi menor. Verificou-se, também, que, nas quantidades de 0,05, 0,10 e 0,20 kg m-2, a palha de trigo proporcionou maior cobertura de solo que a palha de milho. Isso se deve ao maior volume de palha e maior número de peças da palha de trigo em relação à palha de milho, em uma mesma quantidade. A palha de trigo tem menor densidade do que a palha de milho, logo, massas iguais apresentam maior número de peças na palha de trigo.

Notou-se diminuição significativa da concentração de sedimentos na enxurrada com o aumento da quantidade de pal ha, independentemente do tipo da palha. Apesar de, em algumas quantidades, os tipos de pal ha se diferenciarem em relação à cobertura do solo, isso não ocorreu para a concentração de sedimentos.
Os resíduos vegetais na superfície do solo reduzem a desagregação de partículas do solo, por diminuírem a área exposta ao impacto direto das gotas de chuva, reduzindo a concentração de sedimentos na enxurrada. Diminuem, também, a capacidade de transporte do fluxo superficial, por reduzirem a vel oci dade do fluxo e evitarem o impacto direto das gotas de chuva sobre o fluxo, reduzindo sua turbulência. Dessa forma, o fluxo transporta partículas de menor tamanho e, ou, em menor quantidade.

A análise de correlação dos dados mostrou que a concentração de sedimentos na enxurrada relacionase melhor com a percentagem de cobertura do solo do que com a quantidade de pal ha utilizada. Assim, relacionando as concentrações de sedimentos com as percentagens de cobertura do solo (Quadro 2), chegou-se à seguinte equação geral.

$$
\mathrm{C}_{\mathrm{s}}=5,49 \mathrm{e}^{-1,23 \mathrm{Cs}} \quad \mathrm{R}^{2}=0,66 * *
$$

em que $C_{s}$ é a concentração de sedimentos na enxurrada em entressulcos (\%); e é a base do logaritmo natural, e CS é a fração do solo coberto $\left(\mathrm{m}^{2} \mathrm{~m}^{-2}\right)$.

Os pontos experimentais ea curva expressa pela relação (12) estão apresentadas na figura 1.

A redução na concentração de sedimentos na enxurrada foi proporcionalmente maior com as menores quantidades de resíduo vegetal. I sso evidencia a eficácia das pequenas quantidades de resíduos vegetais em reduzir a capacidade de transporte do fluxo superficial, favorecendo a deposição e, conseqüentemente, diminuindo a concentração de sedimentos na enxurrada. Tal concentração pode ter sido reduzida, também, pela redução na taxa de desagregação de solo nas áreas

Quadro 2. Cobertura do solo (CS) e concentração média de sedi mentos $\left(C_{s}\right)$ na enxurrada em entressulcos, considerando o tipo e massa de resíduos (MR) na superfície do solo. Valores são média de 4 repetições

\begin{tabular}{|c|c|c|c|c|c|}
\hline \multirow{2}{*}{$\begin{array}{l}\text { Massa de } \\
\text { resíduos }\end{array}$} & \multicolumn{2}{|c|}{ Cobertura do solo } & \multicolumn{3}{|c|}{ Concentração média de sedimentos } \\
\hline & Palha de trigo ${ }^{(1)}$ & Palha de milho(2) & Palha de trigo & Palha de milho & Média ${ }^{(3)}$ \\
\hline $\mathrm{kg} \mathrm{m}^{-2}$ & $\mathrm{~m}^{2} \mathrm{r}$ & - & 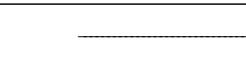 & $\%$ & - \\
\hline $\begin{array}{l}0,00 \\
0,05 \\
0,10 \\
0,20 \\
0,40 \\
0,80\end{array}$ & $\begin{array}{l}0,00 a^{(4)} \\
0,42 a \\
0,62 a \\
0,78 a \\
0,93 a \\
0,99 a\end{array}$ & $\begin{array}{l}0,00 \mathrm{a} \\
0,18 \mathrm{~b} \\
0,37 \mathrm{~b} \\
0,69 \mathrm{~b} \\
0,88 \mathrm{a} \\
0,98 \mathrm{a}\end{array}$ & $\begin{array}{l}6,36 \\
3,50 \\
2,09 \\
2,02 \\
1,59 \\
1,51\end{array}$ & $\begin{array}{l}6,24 \\
4,06 \\
3,49 \\
2,30 \\
2,02 \\
2,60\end{array}$ & $\begin{array}{l}6,30 \\
3,78 \\
2,79 \\
2,16 \\
1,81 \\
2,06\end{array}$ \\
\hline Média & $0,62 \mathrm{a}$ & $0,52 \mathrm{~b}$ & $2,84 b^{(5)}$ & 3,45 a & 3,15 \\
\hline
\end{tabular}

(1) $C S=1-e^{-7,91 M R} R^{2}=0,78^{* *}$. (2) $C S=1-e^{-6,05 M R} \quad R^{2}=0,74 * * .{ }^{(3)} C_{s}=5,49 e^{-1,23 C S} \quad R^{2}=0,66 * *$. (4) para cobertura do solo, médias seguidas da mesma letra, na mesma linha, não diferem estatisticamente pelo teste de Duncan a $5 \%$. ${ }^{(5)}$ para concentração média de sedimentos, médias seguidas de letras diferentes, na mesma linha, diferem estatisticamente pelo teste de Duncan a $5 \%$. 


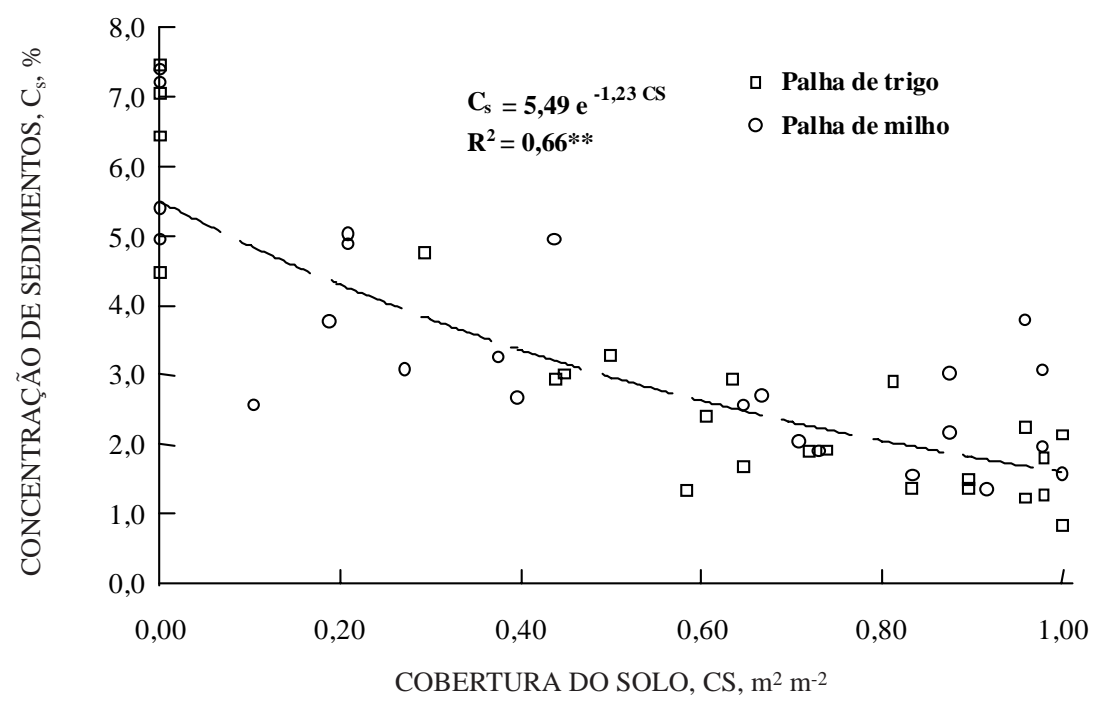

Figura 1. Concentração de sedimentos na enxurrada em entressulcos, em função da cobertura do solo por palha de trigo e palha de milho.

descobertas, em decorrência do aprofundamento do fluxo superficial. Cogo (1981) obteve relações semel hantes entre a concentração de sedimentos na enxurrada e a cobertura do solo por resíduos vegetais.

A erosão em entressulcos ocorreu em taxas variáveis com o tempo de simulação de chuva, como pode ser visto nas figuras $2 \mathrm{a}$ e $2 \mathrm{~b}$. Verificou-se que as taxas deerosão em entressul cos foram crescentes com o tempo de aplicação de chuva, da mesma forma que as taxas de perdas de água (Figura 3). Nas parcelas sem cobertura e naquelas com 0,05 e $0,10 \mathrm{~kg} \mathrm{~m}^{-2}$ de palha de milho, as taxas de erosão em entressulcos cresceram até cerca de $30 \mathrm{~min}$ de chuva e depois tornaram-se decrescentes. Nos demais tratamentos, as taxas de erosão em entressul cos tenderam a estabilizar após um período inicial de crescimento. A tendência de redução das taxas de erosão em entressulcos, após um período inicial de crescimento, verificada nas parcelas sem cobertura do solo, também foi observada por Bradford et al. (1987), Chaves (1987), Moore \& Singer (1990) e Rockenbach (1992).

O crescimento inicial das taxas de erosão está relacionado com o das taxas de perdas de água, que provoca um aumento na capacidade de transporte do fluxo superficial. Assim, noinício da chuva, ofluxo superficial é relativamente pequeno, não tendo capacidade para transportar todo o material desagregado pela ação do impacto das gotas de chuva. À medi da que ofluxo cresce, com otranscorrer do tempo de chuva, torna-se capaz de transportar todo o material desagregado instantaneamente e aquele remanescente do período inicial, quando havia limitação da capacidade de transporte. Deve- se considerar, ainda, que a ação erosiva do impacto da gota aumenta quando a profundidade da lâmina de água na superfície do solo cresce, até atingir $1 / 3$ do diâmetro das gotas de chuva (Mutchler \& Young, 1975). Dessa forma, no início da chuva, a taxa de desagregação em entressulcos pode aumentar dado o limitado aumento na profundidade do fluxo superficial, aumentando, assim, as taxas de erosão em entressulcos.

Em função do aumento da sua capacidade de transporte, o fluxo superficial remove as partículas acumuladas durante o período inicial em que havia limitação da erosão em entressulcos. A partir de então, passa a transportar apenas as partículas desagregadas instantaneamente. Além disso, a redução das taxas de erosão em entressulcos, observada nas parcelas sem cobertura do solo, depois de $30 \mathrm{~min}$ de chuva, pode estar associada a uma limitação da erosão pela taxa de desagregação. Isso pode ser sustentado com base em observações de Moore \& Singer (1990), que verificaram que a taxa de desagregação tornou-se menor com o transcorrer da chuva, em função de uma redução da erodibilidade da camada superficial do solo, produzi da pela remoção sel etiva das partículas mais erodíveis e pela formação de uma camada superficial compactada ou sel o superficial.

No presente estudo, observou-se a formação de sel o superficial nas parcelas com sol o descoberto. Antes da aplicação da chuva, o sol o apresentava microrrelevo caracterizado pela presença de pequenos agregados, deixados pelo preparo realizado previamente, com aspecto poroso "in situ". Com o transcorrer da chuva, os agregados foram destruídos e a superfície do solo tornou-se mais uniforme e compacta. 


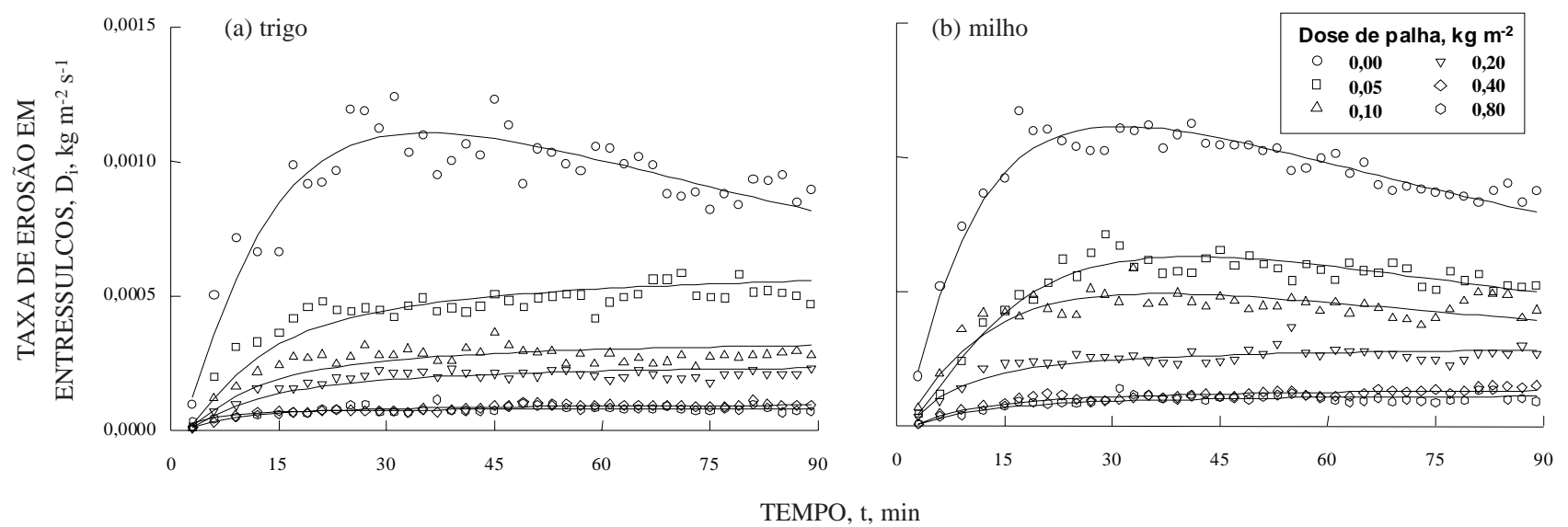

Figura 2. Taxas de erosão em entressulcos, em função do tempo, para diferentes quantidades de palha distribuídas sobre o solo. (a) palha de trigo e (b) palha de milho.

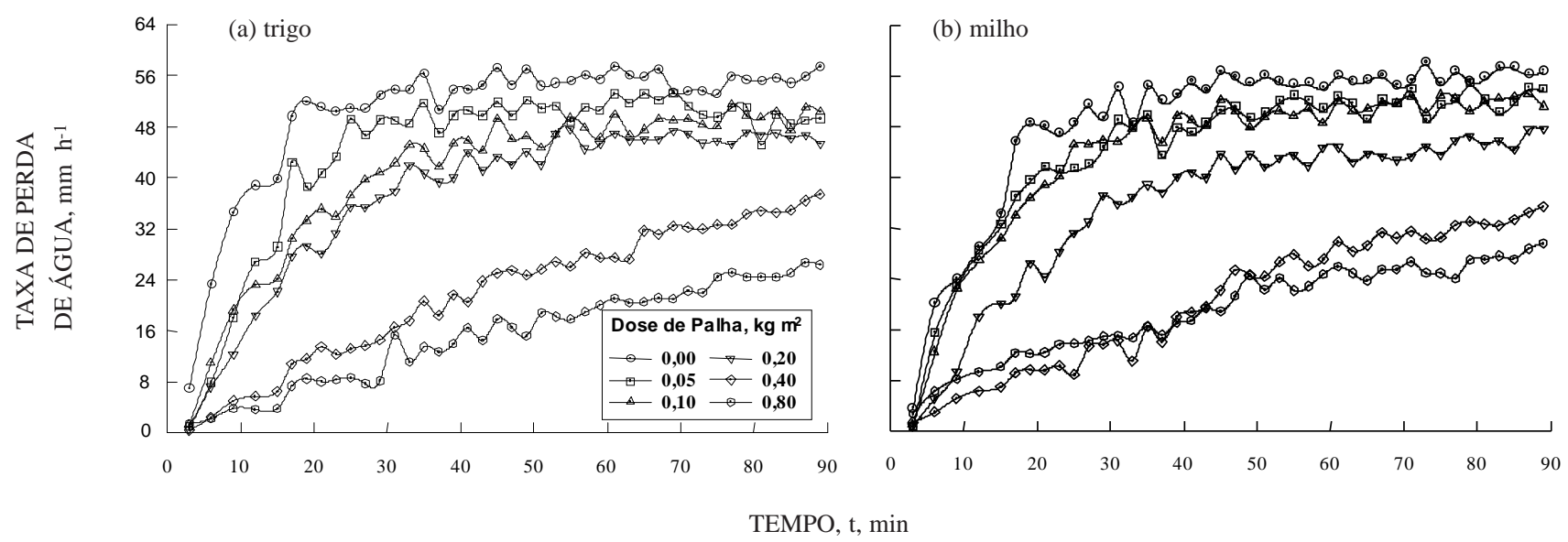

Figura 3. Taxas de perdas de água nos entressulcos, em função do tempo, para diferentes quantidades de palha distribuídas sobre o solo. (a) palha de trigo e (b) pal ha de milho.

Nas parcelas com cobertura dosolo, a importância dos fenômenos supradescritos torna-se menor à medida que aumenta a quantidade de palha distribuída na superfície do solo, pois o efeito da cobertura é predominante. De forma geral, nesses tratamentos, as taxas de erosão em entressulcos foram crescentes no início da chuva, tendendo a tornar-se constantes com o tempo. O crescimento inicial das taxas de erosão em entressulcos pode estar relacionado com o crescimento das taxas de perdas deágua (Figura 3). Entretanto, na presença de resíduos vegetais na superfície do solo, é provável que a capacidade de transporte do fluxo limite a erosão hídrica ao longo de todo o tempo de chuva. Assim, mesmo que ocorram variações nas taxas de desagregação nas áreas descobertas, essas variações não se refletem nas taxas de erosão.
Rockenbach (1992) observou que as taxas de erosão em entressul cos foram decrescentes após um período inicial de crescimento, mesmo nas parcel as com cobertura do solo com pal ha de trigo. Entretanto, esse autor empregou quantidades máximas de $0,08 \mathrm{~kg} \mathrm{~m}^{-2}$ de palha, que são muito semelhantes às menores quantidades de palha usadas no presente estudo $\left(0,05\right.$ e $\left.0,10 \mathrm{~kg} \mathrm{~m}^{-2}\right)$, onde também verificou-se essa tendência de redução das taxas de erosão em entressulcos, principalmente nas parcelas com pal ha de milho. Além disso, a duração da chuva utilizada pelo autor foi de $120 \mathrm{~min}$, enquanto, no presente estudo, a duração da chuva foi de 90 min, sendo possível não ter havido tempo suficiente para que as taxas de erosão em entressul cos se tornassem decrescentes nas parcelas com cobertura. 
O efeito da cobertura dosolo por resíduos vegetais em contato direto com a superfície do solo, dado pel o subfator $C_{i \mid l}$, foi estimado pela equação (6) $\left[C_{i l l}=D_{i \max } /\left(K_{i} i^{2} S_{f}\right)\right]$, em que $D_{\text {imax }}$ é a taxa máxima de erosão em entressulcos, observada na parcela com cobertura do solo.

Para a obtenção do $D_{\text {imax }}$, procedeu-se à análise dos dados, relacionando-se matematicamente as taxas de desagr egação em entressul cos com o tempo de aplicação de chuva, escol hendo-se o model o com maior coeficiente de determinação. Para os tratamentos sem cobertura do solo e com 0,05 e $0,10 \mathrm{~kg} \mathrm{~m}^{-2}$ de palha de milho, o melhor ajuste foi obtido com o model o dado pela seguinte expressão:

$$
D_{i}=f t^{t h}+(j \log (t))
$$

Para os demais tratamentos, o melhor ajuste foi obtido pela expressão:

$$
D_{i}=k e^{(m / t)}
$$

em que $D_{i}$ é a taxa de erosão em entressulcos $\left(\mathrm{kg} \mathrm{m}^{-2} \mathrm{~s}^{-1}\right)$; t é o tempo de aplicação de chuva (min); e é a base do logaritmo natural, e f, h, j, k e m são coeficientes de ajuste que são apresentados no quadro 3.

A partir da derivação da equação (13) ou (14), usadas para o ajuste das taxas de erosão em entressulcos em função do tempo, obtiveram-se os valores de $D_{\text {imax }}$ (ponto de máxima) utilizados no cál culo do subfator $\mathrm{C}_{\mathrm{ill}}$.

Os valores do subfator $C_{i l l}$ observados são apresentados no quadro 4, juntamente com a al tura da lâmina de água estimada pela equação (8) e com os valores estimados do subfator $\mathrm{C}_{i 11}$, por meio das equações (4), proposta por Foster (1982), e (5), proposta por Laflen et al. (1985), para cada tratamento.
Verificou-se que a redução das taxas de erosão em entressulcos pelos resíduos vegetais foi proporcionalmente maior com as menores quantidades de pal ha. Nessas menores quantidades de palha, a redução das taxas de erosão em entressulcos foi mai or quea redução da área exposta ao impacto direto das gotas de chuva. Isso mostra que, além de diminuírem a taxa de desagregação, as pequenas quantidades de resíduo vegetal são também eficientes em diminuir a capacidade de transporte do fluxo superficial, evitando que as partículas desagregadas, nas áreas expostas ao impacto direto das gotas de chuva, sejam transportadas para os sulcos.

Para uma dose de $0,05 \mathrm{~kg} \mathrm{~m}^{-2}$ de pal ha de milho, a área coberta foi de 0,18 $\mathrm{m}^{2} \mathrm{~m}^{-2}$ (Quadro 2), ou seja, a área exposta ao impacto das gotas de chuva foi reduzida em 18\%; portanto, se a redução da erosão em entressulcos fosse devida somente à da área exposta, ter-se-ia uma redução de $18 \%$ nas taxas de erosão. Entretanto, considerando o subfator $C_{i \mid l}$ de 0,59 neste tratamento (Quadro 3), significa afirmar que com esta cobertura a erosão será reduzida para $59 \%$ daquela que ocorreria se o solo estivesse descoberto. Assim, pode-se dizer que houve uma redução de $41 \%$ na erosão em entressulcos com a aplicação de $0,05 \mathrm{~kg} \mathrm{~m}^{-2}$ de palha de milho. Dessa forma, 23 pontos percentuais da redução na erosão em entressul cos são devidos aos efeitos da pal ha sobre o transporte de sedimentos pel o fluxo superficial e a uma possível redução da taxa de desagregação pelo aumento da profundidade do fluxo superficial, uma vez que o efeito direto da cobertura seria de apenas $18 \%$, correspondente à área coberta pel o resíduo.

Da mesma forma, para a palha de trigo, o maior efeito sobre ofluxo superficial foi observado na dose de $0,10 \mathrm{~kg} \mathrm{~m}^{-2}$, quereduziu a área exposta ao impacto

Quadro 3. Valores dos coeficientes de ajuste e dos coeficientes de determinação das equações (13)

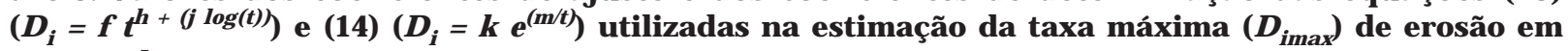

\begin{tabular}{|c|c|c|c|c|c|c|c|}
\hline Palha & Massa de resíduo & $f\left(x 10^{-5}\right)$ & $\mathbf{h}$ & $\mathbf{j}$ & $k\left(\times 10^{-4}\right)$ & $\mathbf{m}$ & $\mathbf{R}^{2}$ \\
\hline & $\mathrm{kg} \mathrm{m}^{-2}$ & & & & & & \\
\hline \multirow[t]{6}{*}{ Trigo } & 0,00 & 1,147 & 2,559 & $-0,825$ & - & - & $0,92 * *$ \\
\hline & 0,05 & - & - & - & 6,226 & $-9,86$ & $0,92 * *$ \\
\hline & 0,10 & - & - & - & 3,512 & $-9,08$ & $0,88^{* *}$ \\
\hline & 0,20 & - & - & - & 2,593 & $-9,46$ & $0,94 * *$ \\
\hline & 0,40 & - & - & - & 1,019 & $-6,70$ & $0,94 * *$ \\
\hline & 0,80 & - & - & - & 0,859 & $-3,22$ & $0,63 * *$ \\
\hline \multirow[t]{6}{*}{ Milho } & 0,00 & 2,892 & 2,123 & $-0,710$ & - & - & $0,97 * *$ \\
\hline & 0,05 & 0,273 & 2,928 & $-0,907$ & - & - & $0,98 * *$ \\
\hline & 0,10 & 1,183 & 2,069 & $-0,660$ & - & - & $0,90 * *$ \\
\hline & 0,20 & - & - & - & 3,038 & $-6,36$ & $0,93 * *$ \\
\hline & 0,40 & - & - & & 1,450 & $-8,21$ & $0,95^{* *}$ \\
\hline & 0,80 & - & - & - & 1,224 & $-8,31$ & $0,91 * *$ \\
\hline
\end{tabular}
entressulcos 
Quadro 4. Cobertura do solo (CS), altura da lâmina deágua (y) e subfator cobertura do solo em entressulcos, para resíduos vegetais em contato direto com a superfície $\left(C_{i l l}\right)$, considerando o tipo de palha e massa de resíduos vegetais em cobertura. Valores observados e estimado pelas equações propostas por F oster (1982) e Laflen et al. (1985)

\begin{tabular}{|c|c|c|c|c|c|c|}
\hline \multirow{2}{*}{ Tipo de palha } & \multirow{2}{*}{ Massa de resíduo } & \multirow{2}{*}{ CS } & \multirow{2}{*}{$y^{(1)}$} & \multirow{2}{*}{$C_{i l l}$ observado $^{(2)}$} & \multicolumn{2}{|c|}{$\mathrm{C}_{\mathrm{iII}}$ estimado } \\
\hline & & & & & Foster ${ }^{(3)}$ & Laflen $^{(4)}$ \\
\hline & $\mathrm{kg} \mathrm{m}^{-2}$ & $\mathrm{~m}^{2} \mathrm{~m}^{-2}$ & $\mathrm{~mm}$ & & & \\
\hline \multirow[t]{6}{*}{ Trigo } & 0,00 & 0,00 & 0,14 & 1,00 & 1,00 & 1,00 \\
\hline & 0,05 & 0,42 & 0,15 & 0,53 & 0,58 & 0,35 \\
\hline & 0,10 & 0,62 & 0,19 & 0,26 & 0,36 & 0,21 \\
\hline & 0,20 & 0,78 & 0,24 & 0,22 & 0,19 & 0,14 \\
\hline & 0,40 & 0,93 & 0,31 & 0,10 & 0,06 & 0,10 \\
\hline & 0,80 & 0,99 & 0,52 & 0,08 & 0,01 & 0,09 \\
\hline \multirow[t]{6}{*}{ Milho } & 0,00 & 0,00 & 0,14 & 1,00 & 1,00 & 1,00 \\
\hline & 0,05 & 0,18 & 0,17 & 0,59 & 0,80 & 0,64 \\
\hline & 0,10 & 0,37 & 0,18 & 0,57 & 0,60 & 0,40 \\
\hline & 0,20 & 0,69 & 0,20 & 0,22 & 0,29 & 0,18 \\
\hline & 0,40 & 0,88 & 0,20 & 0,13 & 0,11 & 0,11 \\
\hline & 0,80 & 0,98 & 0,22 & 0,09 & 0,02 & 0,09 \\
\hline
\end{tabular}

(1) $y=$ altura da lâmina de água estimada pela equação $\mathbf{y}=\left[(\mathbf{n} \mathbf{q}) /\left(\mathbf{s}^{\mathbf{1} / 2}\right)\right]^{3 / 5}$ para sol os com cobertura e pela equação $\mathbf{y = Q} /(\mathbf{I} \mathbf{v})$ para solo

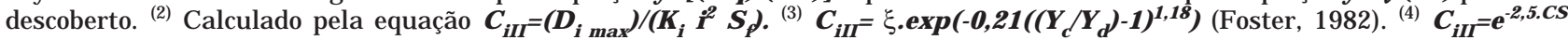
(Laflen et al., 1985).

das gotas de chuva em $62 \%$ (CS $=0,62)$ e reduziu a erosão em entressul cos em $74 \%\left(C_{i \mid l}=0,26\right)$, ou seja, uma redução de 12 pontos percentuais decorrente deoutros efeitos que não o da cobertura do solo. Esses resultados mostram que pequenas quantidades de palha de milho, apesar de não cobrirem o solo tão eficientemente quanto a mesma quanti dade de pal ha de trigo, são igualmente eficientes em reduzir a erosão em entressulcos, considerando seus efeitos sobre o fluxo superficial.

Os resultados apresentados no quadro 4 mostram que, nas parcelas com aproximadamente $100 \%$ de cobertura, o subfator $\mathrm{C}_{\mathrm{ill}}$ observado foi em média igual a 0,08, demonstrando que, mesmo nessas condições, ocorreu erosão em entressulcos. I sso não era esperado, pois, nessas condições, não há desagregação do solo pelo impacto das gotas de chuva. Entretanto, o solo em estudo tem uma agregação muito fraca, estando muito desagregado em função do preparo efetuado antes dos testes. Assim, partículas desagregadas pel o preparo foram transportadas pel o fluxo superficial existente sob os resíduos vegetais, resultando em uma taxa de erosão ainda mensurável.

O uso da equação (4), proposta por F oster (1982), para estimar o subfator $\mathrm{C}_{\mathrm{ill}}$, superestimou-o para as menores doses de palha e subestimou-o para as maiores doses de palha, em relação aos valores observados, principalmente para a pal ha de milho.

A superestimação do subfator $C_{i l l}$, verificada nas menores quantidades de pal ha, podeter sido causada por uma subestimação da profundidade do fluxo superficial nas parcelas com cobertura ou, então, porque na equação (4), proposta por F oster (1982), o efeito dos resíduos vegetais sobre o fluxo superficial está subdimensionado, sendo necessário fazer melhor cali bração do model o para as condições estudadas.

A subestimação do subfator $C_{i l l}$, verificada nas maiores quantidades de palha, ocorre porque a equação (4) supõe que com $100 \%$ de cobertura as perdas de solo tendam a zero. No entanto, no presente estudo, verificou-se que com $99 \%$ de cobertura houve perdas mensuráveis de solo, provavelmente porque o solo foi preparado pouco antes dos testes.

Rockenbach (1992), trabalhando com palha de trigo e com cobertura máxima de $72 \%$ da superfície do solo, também observou que a equação (4) subestimou o subfator $C_{i l l}$. Nesse caso, porém, a redução nas taxas de erosão foi sempremenor quea redução na área exposta ao impacto direto das gotas de chuva. I sso inviabiliza o uso da equação (4), que pressupõe ser a redução na erosão em entressulcos sempre maior que a redução na área exposta ao impacto direto das gotas de chuva.

A equação (5) proposta por Laflen et al. (1985) para estimar o subfator $C_{i l l}$ é mais simples, baseando-se exclusivamente na cobertura do solo obtida com os resíduos vegetais.

A equação (5) produziu estimativas do subfator $\mathrm{C}_{\text {ill }}$ mais consistentes com os dados observados, com exceção para as menores quantidades de palha de 
trigo, cujos valores estimados são menores que os observados. Assim, procedeu-se ao ajuste dos dados observados ao modelo proposto por Laflen et al. (1985), obtendo-se as seguintes relações:

Para palha de trigo:

$$
C_{i l l}=e^{2,31} \mathrm{CS} \quad\left(R^{2}=0,94 * *\right)
$$

Para palha de milho:

$$
\mathrm{C}_{\text {ill }}=\mathrm{e}^{-2,33 \mathrm{CS} \quad\left(\mathrm{R}^{2}=0,97 * *\right)}
$$

Para os dois tipos de palha:

$$
\mathrm{C}_{\mathrm{ill}}=\mathrm{e}^{-2,32 \mathrm{CS} \quad\left(\mathrm{R}^{2}=0,96 * *\right)}
$$

em que $C_{i l l}$ é o subfator referente à cobertura em contato direto com a superfície do solo; eéa base do logaritmo natural, eCS éa cobertura do solo $\left(\mathrm{m}^{2} \mathrm{~m}^{-2}\right)$. Na figura 4, observa-se a curva obtida com a equação (17).

As relações do subfator $C_{i l l}$ com a cobertura do solo, obtidas no presente trabalho, são muito semelhantes àquelas propostas por Laflen et al. (1985), reforçando a adequação do model o proposto para a estimação desse subfator. Por ser um model o mais simples, com parâmetros mais fáceis de serem obtidos, sua difusão para aplicação na estimativa do subfator $\mathrm{C}_{\mathrm{ill}}$ é proposta.

Os resultados obtidos não permitem distinguir os efeitos das palhas de trigo e de milho quanto à eficiência de controle da erosão em entressulcos. Dessa forma, a estimação do subfator $C_{i l l}$, para os dois tipos de palha, pode ser feita pela equação (17), a partir da fração de solo coberto pelos resíduos vegetais em contato direto com a superfície do solo nas regiões em entressulcos.

\section{CONCLUSÕES}

1. A erosãoem entressulcos decresceu exponencialmente com o aumento da cobertura do solo por resíduos vegetais. Nas parcelas com cerca de $100 \%$ de cobertura, a erosão em entressul cos foi reduzida em $92 \%$ em relação ao solo descoberto.

2. Não foram encontradas diferenças entre a pal ha de milho e a palha de trigo, quanto à eficácia em controlar a erosão em entressulcos. A palha de milho, em pequenas quantidades, apesar de não cobrir osol otanto quantoa pal ha detrigo, foi tão eficaz quanto esta no controle da erosão em entressulcos.

3. Nas parcelas de solo descoberto, as taxas de erosão em entressulcos foram crescentes com o tempo de chuva, até atingirem um valor máximo, tornando-se, então, decrescentes.

4. As relações do subfator $C_{i l l}$ com a cobertura do solo, obtidas no presente trabal ho, foram muito semelhantes àquelas propostas por Laflen et al . (1985), reforçando a adequação do model o proposto para a estimação desse subfator.

\section{LITE RATURA CITADA}

ABRÃO, P.U.R.; GIANLUPPI, D. \& AZOLIM, M.A.D. Levantamento semidetalhado dos solos da estação experimental desilvicultura de Santa Maria. Porto Alegre, Instituto de Pesquisas de Rescursos Naturais Renováveis, 1988. 75p. (Publicação I PRNR, 21)

AL DURRAH, M.M. \& BRADFORD, J.M. The mechanism of raindrop splash on soil surfaces. Soil Sci. Soc. Am. J ., 46:1086-1090, 1982.

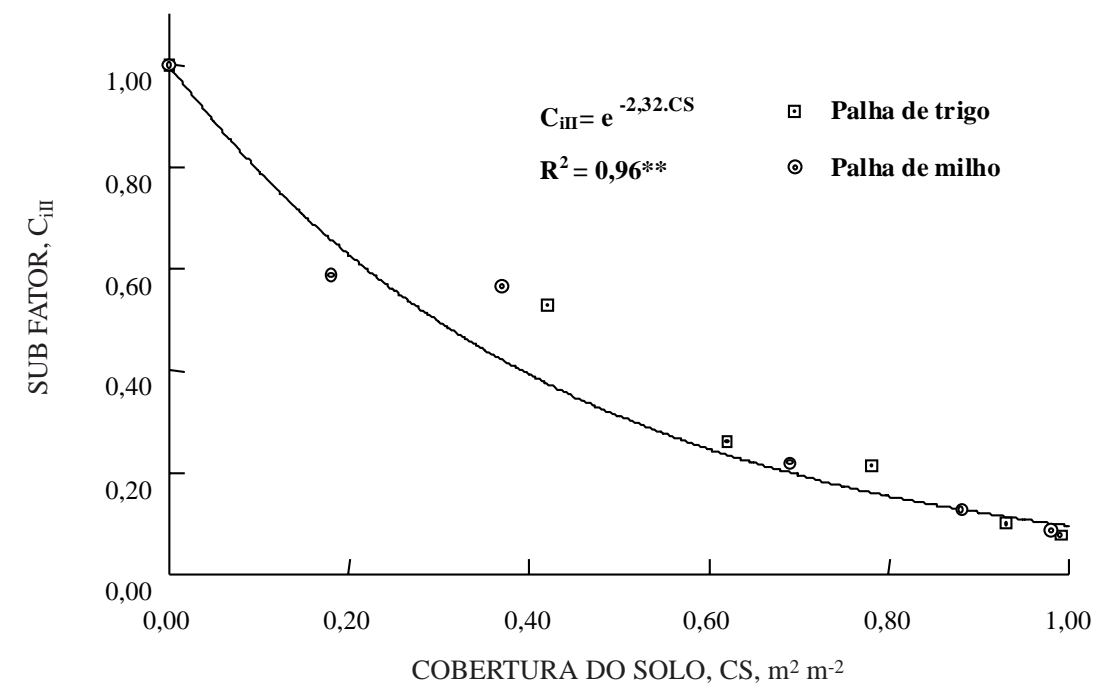

Figura 4. Subfator cobertura em contato direto com a superfície do solo $\left(C_{i I I}\right)$, considerando a cobertura do solo (CS) por diferentes quantidades de resíduos vegetais em entressulcos, segundo a equação (17), $C_{\text {ill }}=\mathrm{e}^{-2,32 C S}$. 
BRADFORD, J .M.; FERRIS, J .E. \& REMLEY, P.A. Interrill soil erosion processes: I. Effect of surface sealing on infiltration, runoff and soil splash detachment. Soil Sci. Soc. Am. J., 51:1566-1571, 1987.

BRAIDA, J.A. Relações da erosão em entressulcos com resíduos vegetais em cobertura e erosão em sulcos em um solo Podzólico Vermelho-Escuro. Porto Alegre, Universidade Federal do Rio Grande do Sul, 1994. 150p. (Tese de Mestrado)

BRAIDA, J.A. \& CASSOL, E.A. Erodibilidade em sulcos e em entressulcos de um Podzólico Vermelho-Escuro franco arenoso. R. Bras. Ci. Solo, 20:127-134, 1996.

CASSOL, E.A. \& GUERRA, M. Calibração do primeiro aparel ho simulador de chuvas de braços rotativos do estado do Rio Grande do Sul. In: ENCONTRO NACIONAL DE PESQUISA SOBRE CONSERVAÇÃO DO SOLO, 2., PasSo Fundo, 1978. Anais. Passo Fundo, EMBRAPA/Centro Nacional de Pesquisa do Trigo, 1978. p.29-39.

CHAVES, H.M.L. Influence of incorporated crop residue on interrill erosion. West Lafayette, Purdue University, 1987. 143p. (Tese de Mestrado)

CHOW, V.T. Open-channel hydraulics. New York, McGraw-Hill, 1959. 680p.

COGO, N.P. Effect of residue cover, tillage induced roughness, and slope length on erosion and related parameters. West Lafayette, Purdue University, 1981. 346p. (Tese de Doutorado)

ELLISON, W.D. Soil erosion studies. Agric. Eng., 28:145-146, 197201, 245-248, 297-300, 349-351, 402-405, 442-444, 1947.

EMPRESA BRASILEIRA DE PESQUISA AGROPECUÁRIA EMBRAPA. Manual de métodos de análise do solo. Rio de J aneiro, Ministério da Agricultura, 1979. Não paginado.

FOSTER, G.R. Modeling the erosion process. In: HAAN, C.T., ed. Hydrologic modeling of small watersheds. St. J oseph, American Society of Agricultural Engineers, 1982. p.297380. (ASAE Monograph, 5)

FOSTER, G.R.; J OHNSON,C.B. \& MOLDENHAUER, W.C. Hydraulics of failure of unanchored cornstalk and wheat straw mulches for erosion control. Trans. Am. Soc. Agric. Eng., 25:940-947, 1982.

KINNEL, P.I.A. The influence of flow discharge on sediment concentrations in raindrop induced flow transport. Aust. J . Soil Res., 26:575-562, 1988.
LAFLEN, J .M.; FOSTER, G.R. \& ONSTAD, C. Simulation of individual storm soil losses for modeling the impact of soil erosion on cropland productivity. In: EL-SWAFY, MOLDENHAUER \& LO, eds. Soil erosion and conservation. Ankeny, Soil Conservation Society of American, 1985. p.285295.

LIEBENOW, A.M.; ELLIOT, W.J .; LAFLEN, J .M. \& KOHL, K.O. Interrill erodibility: collection and analysis of data from cropland soils. Trans. Am. Soc. Agric. Eng., 33:1882-1888, 1990.

LOPES, P.R.C.; COCO, N.P. \& LEVIEN, R. Eficácia relativa de tipo e quantidade de resíduos culturais espalhados uniformemente sobre o solo na redução da erosão hídrica. R. Bras. Ci. Solo, 11:71-75, 1987.

LOPES, P.R.C. Relações da erosão com tipos e quantidades de resíduos culturais espal hados uniformemente sobre o solo. Porto Alegre, Universidade Federal do Rio Grande do Sul, 1984. 116p. (Tese de Mestrado)

MEYER, L.D.; FOSTER, G.R. \& RÖMKENS, M.J.M. Source of soil eroded by water from upland slopes. In: PRESENT and prospective technology for predicting sediment yields and sources. Washington, USDA-Agricultural Research, 1975. p.177-189. (ARS-S-40)

MOORE, D.C. \& SINGER, M.J . Crust formation effects on soil erosion processes. Soil Sci. Soc. Am. J ., 54:1117-1123, 1990.

MUTCHLER, C.K. \& YOUNG, R.A. Soil detachment by raindrops. In: PRESENT and prospective technology for predicting sediment yields and sources. Washington, USDAAgricultural Research, 1975. p.113-117. (ARS-S-40)

ROCKENBACH, C.A. Erosão em entressulcos sob diferentes coberturas por resíduos de trigo em um solo Podzólico Vermelho-Amarelo sob chuva simulada. Porto Alegre, Universidade Federal do Rio Grande do Sul, 1992. 108p. (Tese de Mestrado)

TEDESCO, M.J .; VOLKWEISS, S.J . \& BOHNEN, H. Análises de solo, plantas e outros materiais. Porto Alegre, Universidade Federal do Rio Grande do Sul, 1985. 188p. (Boletim Técnico, 5)

WISCHMEIER, W.H. Estimating the soil loss equations cover and management factor for undisturbed areas. In: PRESENT and prospective technology for predicting sediment yields and sources. Washington, USDAAgricultural Research, 1975. p.118-124. (ARS-S-40) 